\title{
Advanced ceramic components with embedded sapphire optical fiber sensors for high temperature applications
}

\author{
Amir Ghazanfari ${ }^{\text {a, }}$, Wenbin $\mathrm{Li}^{\mathrm{a}}$, Ming C. Leu ${ }^{\mathrm{a}}$, Yiyang Zhuang ${ }^{\mathrm{b}}$, Jie Huang ${ }^{\mathrm{b}}$ \\ ${ }^{a}$ Mechanical and Aerospace Engineering Department, Missouri University of Science and \\ Technology, Rolla, MO, USA \\ ${ }^{\mathrm{b}}$ Electrical and Computer Engineering Department, Missouri University of Science and \\ Technology, Rolla, MO, USA
}

\begin{abstract}
$\underline{\text { Abstract }}$
This paper describes an extrusion-based additive manufacturing process that has been developed to enable embedment of sapphire optical fiber sensors in ceramic components during the part fabrication. In this process, an aqueous paste of ceramic particles is extruded through a moving nozzle to build the part layer-by-layer. In the case of sensor embedment, the fabrication process is halted after a certain number of layers have been deposited; the sensors are placed in their predetermined locations, and the remaining layers are deposited until the part fabrication is completed. Because the sensors are embedded during the fabrication process, they are fully integrated with the part and the problems of traditional sensor embedment can be eliminated. Scanning electron microscopy was used to observe the embedded sensors and to detect any possible flaws in the part or embedded sensor. Attenuation of the sensors was measured in nearinfrared region (1500-1600 $\mathrm{nm}$ wavelength). Standard test methods were employed to examine the effect of embedded fibers on the strength and hardness of the parts. The results indicated that the sapphire fiber sensors with diameters smaller than 250 micrometers were able to endure the freeform extrusion fabrication process and the post-processing without compromising the part properties.
\end{abstract}

Keywords: ceramic on demand extrusion; extrusion freeforming; additive manufacturing; smart material; smart structure; alumina.

\section{Introduction}

Embedded sensors have been widely used in structural health monitoring and proven very effective in civil and structural engineering $[1,2]$. However, there are currently no viable techniques for in-situ monitoring of the health status of the critical components in energy production systems. In addition, the existing techniques for process monitoring are inadequate to operate reliably in the extremely harsh environments over a long time [3]. The sensing capabilities can be incorporated in the design phase of various energy systems by embedding sensors into the critical components, enabling a new paradigm in harsh-environment sensing. The embedded sensors not only provide the real-time information on the health status of the component, but also reduce the complexity in sensor installation and increase the robustness of the sensors for reliable measurements of various parameters that are important for system control and optimization.

\footnotetext{
*Corresponding author (amir.ghazanfari@ mst.edu)
} 
Embedded sensors are conventionally attached to or mounted on the component after the structure is fabricated. Several embedment techniques for strain sensors have been proposed in the literature [4-10]. However, these techniques could result in an unsecured sensor attachment, offsets between the sensor readings and the actual status of the structure, potential performance degradation of the host materials or structures, and relative slip at the interface of the matrix and sensor encapsulation [11-15]. For strain measurements, in most cases, the strain sensitivity of an embedded sensor is significantly different from that of the bare sensor [2]. In harsh environments, the sensors are either surface mounted far from critical locations to avoid interference with the operation of the structures, or destructively inserted into the critical locations through appropriate channels in the structures, making it difficult to provide measurements with a high spatial and temporal resolution [16]. Additive manufacturing (AM) is potentially a promising method that could be employed to embed the sensors into the host structure during the component fabrication. This allows secured sensor placement, enhances the survivability, improves the measurement accuracy and reliability, and preserves the structural integrity of the parts.

AM has been recently exploited to embed fibers, sensors or other components in parts to enhance the properties of parts (e.g., strengthen them) or produce smart components. Most of the research in this area is based on ultrasonic consolidation (UC) or ultrasonic additive manufacturing (UAM) process. Janaki et al. [17] used this process to embed SiC fibers and stainless wire meshes in an $\mathrm{Al} 3003$ matrix and produced fiber-reinforced metal matrix composites. Li et al. [18] embedded fiber Bragg gratings (FBG) in metal foil using UC processes and investigated the embedding process, cross-sections of welded samples, the form change and wavelength shift of the Bragg peak during the processes, and the sensing characteristics of the embedded FBGs. Maier et al. [19] embedded optical fiber sensors incorporating FBGs in a polymeric component made by the selective laser sintering process. Dapino [20] also used UC to fabricate Galfenol beams for adaptive vibration absorbers, NiTi/Al composites for zero coefficient of thermal expansion applications, and structures with embedded cooling channels. Monaghan et al. [21] exploited UC to integrate optical fibers equipped with metallic coatings into solid aluminum matrices. They also characterized the inter-laminar and fiber/matrix interfaces and examined their bonding strength. In another paper [22], they embedded three dielectric materials into aluminum metal-matrices produced by the UC process and investigated the effect of the dielectric material hardness on the final metal matrix mechanical strength. Kousiatza and Karalekas [23] embedded FGBs in thermoplastic parts during their fabrication process in a fused deposition modeling system for in-situ and real-time monitoring of strain fields and temperature profiles as the parts were being built.

Because of their high melting point and excellent resistance to oxidation, chemical attack and erosion, advanced ceramics are the best candidates for host materials in harsh and corrosive environments of energy production systems. Several AM techniques have been developed or modified to fabricate three-dimensional ceramic components, including 3D printing, ink-jet printing, selective laser sintering, stereolithography, laminated object manufacturing, and extrusion-based techniques (mainly fused deposition of ceramics, robocasting, and freeze-form extrusion fabrication). All of these techniques involve adding ceramic materials layer by layer. A comprehensive review on additive manufacturing of ceramic-based materials was recently published by Travitzky et al. [24]. However, these processes are either incapable of producing a mechanically strong part, or embedding a sensor in the part during fabrication is infeasible. Thus, 
development of a process for manufacturing high-strength advanced ceramics with embedded sensors could be very beneficial to this field.

Due to their small size, light weight, immunity to electromagnetic interference, multiplexing and distributed sensing capability, resistance to chemical corrosion, and remote operation capability, optical fiber sensors are by far the best candidates to be embedded in parts. FBG is the most successful fiber optic sensor and has shown great advantages for integrating with AM techniques. FBGs consist of periodic refractive index variations written by an intense ultraviolet (UV) laser. These periodic variations, also called Bragg grating, have a certain period that can be encoded by an optical resonant wavelength, and by tracking the resonant wavelength shift, one can detect the strain applied on the FBG, making it a good candidate for strain measurement. However, it has been found that the UV laser induced material variations could be easily erased if the ambient temperature is higher than $450{ }^{\circ} \mathrm{C}$, making it inapplicable for strain sensing under high temperature (up to $1000{ }^{\circ} \mathrm{C}$ ) [25]. In some particular applications, such as high temperature material characterization, coal gasifier health monitoring, turbine crack detection, or structural health monitoring of the leading edge of a wing, strain sensors that can survive in extreme temperatures are needed. Most of the optical fiber sensors are made of silica glass and their longterm reliability above $1000{ }^{\circ} \mathrm{C}$ has been a concern due to the degradation of optical properties and mechanical strength. To further increase the operating temperatures, researchers have turned to sapphire fibers which have a melting point of $2050{ }^{\circ} \mathrm{C}$, low optical loss in a large spectrum window, superior mechanical strength, and excellent resistance to chemical corrosion [26]. Very recently, constructing a sensor on an optical sapphire fiber for use in temperatures up to $1400{ }^{\circ} \mathrm{C}$ has been successfully demonstrated by Huang et al. [27]. As a result, technologies for the embedment of sapphire fiber sensors for high temperature applications are highly needed.

In this paper, a freeform extrusion fabrication process for the fabrication of solid ceramic components, called Ceramic On-Demand Extrusion (CODE), is employed to embed sapphire optical fiber sensors in alumina parts for high-temperature sensing. Micrographs of embedded fibers are examined, optical attenuation is measured, and the effect of embedded fiber on parts density, shrinkage, strength, and hardness is examined.

\section{Methodology}

\subsection{Materials and paste preparation}

Unjacketed sapphire fibers of $5 \mathrm{~cm}$ length and 125/250 $\mu \mathrm{m}$ diameter (SF125-5 and SF250-5, MicroMaterials Inc., Tampa, FL, USA) produced by a laser heated pedestal growth system were purchased to be embedded into the parts. Both ends of all the fibers were polished by the manufacturer to minimize transmission losses. The fiber properties are listed in Trable 1.

\begin{tabular}{|c|c|c|c|}
\hline \multicolumn{4}{|c|}{ Table 1. Fiber characteristics. } \\
\hline Name & $\begin{array}{c}\text { Fiber } \\
\text { orientation }\end{array}$ & $\begin{array}{c}\text { Tensile } \\
\text { strength }\end{array}$ & Attenuation $^{*}$ \\
\hline $\begin{array}{c}\text { SF125-5, } \\
\text { SF250-5 }\end{array}$ & C-axis & $2.2 \mathrm{GPa}$ & $0.5-1.0 \mathrm{~dB}$ \\
\hline
\end{tabular}


The paste is composed of a commercially available alumina powder (A-16SG, Almatis Inc., Leetsdale, PA, USA), deionized water, ammonium polymethacrylate (DARVAN® C-N, Vanderbilt Minerals, Norwalk, CT, USA), and cold-water-dispersible methylcellulose (Methocel J5M S, Dow Chemical Company, Midland, MI, USA). The powder properties are listed in TTable 2 .

Table 2. Powder characteristics.

\begin{tabular}{|c|c|c|c|c|}
\hline Name & Particle size & Surface area & Purity & $\begin{array}{c}\text { Max. fired } \\
\text { density }\end{array}$ \\
\hline A-16SG & $0.34 \mu \mathrm{m}$ & $9.44 \mathrm{~m}^{2} / \mathrm{g}$ & $99.8 \%$ & $3.95 \mathrm{~g} / \mathrm{cm} 3$ \\
\hline
\end{tabular}

The alumina powder was dispersed in water using $1 \mathrm{mg}$ Darvan $\mathrm{C}$ per square meter of surface area of power and then ball-milled for about 15 hours to break up agglomerates and to produce a uniform mixture. Methylcellulose was dissolved in water $(<1 \mathrm{vol} \%)$ and was used as a binder to increase paste viscosity and to assist in forming a stronger green body after drying. A vacuum mixer (Model F, Whip Mix, Louisville, KY, USA) was employed to mix the paste homogeneously without introducing air for 12 minutes. Finally, a vibratory table (Syntron Material Handling, Saltillo, MS, USA) was used to remove the remaining air bubbles.

\subsection{Processing}

The Ceramic On-Demand Extrusion process [28] was used to fabricate the parts. In this AM process, ceramic paste is extruded at controlled flowrates through a circular nozzle. The nozzle is attached to a motion system, which is capable of moving in $\mathrm{X}, \mathrm{Y}$ and $\mathrm{Z}$ directions through $\mathrm{G} \&$ $\mathrm{M}$ code commands provided by an indigenously developed tool-path planning software. The extrudate is deposited on a substrate located in a tank designed to hold a fluid medium. Once the deposition of each layer is completed, a liquid feeding subsystem pumps a mineral oil into the tank surrounding the layer to preclude undesirable evaporation from the sides of the deposited layers.

The oil level is monitored and controlled by LabVIEW (National Instruments Corp., Austin, TX, USA) using a closed loop system so that it reaches just below the top surface of the part being fabricated. The subsystem begins with an input from the G \& M code signaling a desired oil level. The desired oil level is compared to the actual level, given by a level sensor, to produce an error. This error is sent to a PID controller to send a command voltage to a micro gear pump to control the oil flow rate. For parts with internal structures, a sparse sacrificial layer with a serpentine pattern is printed before building the part. This layer allows flow of oil into the internal structures.

Infrared radiation is then used to uniformly dry the deposited layer so that the part being fabricated can maintain its shape when the next layers are being deposited on top of it. The part is fabricated in a layer-by-layer fashion by repeating the layered deposition followed by layered radiation drying with a liquid surrounding the already deposited layers. If a sensor is to be embedded, the fabrication process is halted after a certain number of layers have been deposited. The sensors are placed in their predetermined locations, and the remaining layers are deposited. Once the fabrication process is completed, the remaining water in the fabricated part is removed 
further by bulk drying to obtain green parts. The post-processing includes removing the binder content at elevated temperatures and sintering the part.

Six alumina blocks were fabricated and five sapphire fibers of the same diameter were embedded in each block. The as-printed size of the blocks was $32 \times 28 \times 4.4 \mathrm{~mm}^{3}$ (length, width, and height, respectively). A fixture was employed to place the fibers accurately in their predetermined locations in the longitudinal direction of the blocks as shown in Figure 1. Three of the blocks had fibers of $125 \mu \mathrm{m}$ diameter embedded in them while the other three contained 250 $\mu \mathrm{m}$ fibers. A nozzle (Gauge 20 Precision Needle, Integrated Dispensing Solutions Inc., Agoura Hills, CA, USA) with a length of $6.3 \mathrm{~mm}$ and an internal diameter of $0.61 \mathrm{~mm}$ was used to deposit the paste. Nozzle travel speed, layer thickness, and line spacing were $30 \mathrm{~mm} / \mathrm{s}, 0.4 \mathrm{~mm}$, and $0.6 \mathrm{~mm}$, respectively.

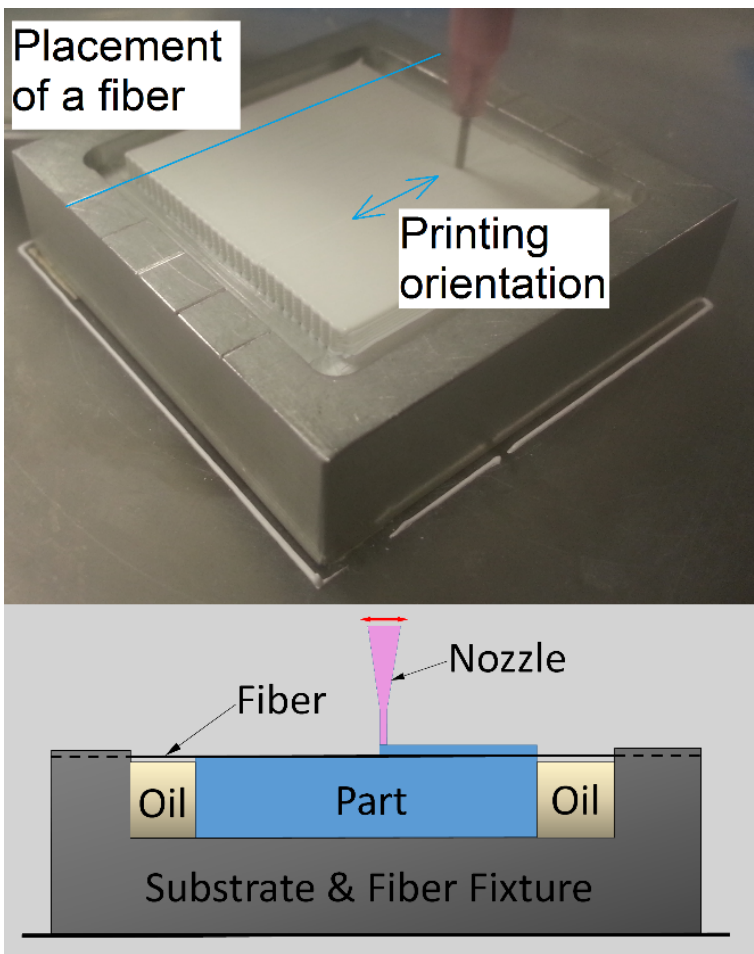

Figure 1. An alumina block with embedded sensors during the fabrication process.

\subsection{Post processing}

Two different methods were used to remove the remaining water in the parts. In the first approach, water in the parts was first frozen and then removed through sublimation by using a freeze dryer (Genesis 25L, VirTis, Stone Ridge, NY, USA). The temperature was set at $-10{ }^{\circ} \mathrm{C}$ and pressure at $2.0 \mathrm{~Pa}$ (15 mTorr) for three days. This drying method was used for one block with $125 \mu \mathrm{m}$ fibers and one block with $250 \mu \mathrm{m}$ fibers. Humid drying was used as an alternative approach for the other parts. An environmental chamber (LH-1.5, Associated Environmental Systems, Ayer, MA, USA) was used to set the temperature and humidity during the drying process at $75 \%$ relative humidity and $25{ }^{\circ} \mathrm{C}$ for the first $4-6$ hours of drying. This condition guarantees successful drying (i.e. no cracks or warpage). After the first stage of drying, the 
shrinkage ends and higher drying rates could be achieved, without introducing flaws, by increasing the temperature. This drying method was used for the remaining four blocks.

A heating rate of $1{ }^{\circ} \mathrm{C} / \mathrm{min}$ was chosen for the binder burnout process to avoid large weight reduction rates. The parts were maintained at $450{ }^{\circ} \mathrm{C}$ for two hours. The samples were then sintered with a heating rate of $5{ }^{\circ} \mathrm{C} / \mathrm{min}$ in an electric furnace (Deltech Inc., Denver, CO, USA). They were sintered at $1550{ }^{\circ} \mathrm{C}$ for $1.5 \mathrm{~h}$ and cooled down to room temperature at $10{ }^{\circ} \mathrm{C} / \mathrm{min}$ rate.

\subsection{Measuring attenuation}

Attenuation of the fibers before and after embedment was measured using a tunable FabryPerot InGaAsP laser source (8168F, Hewlett-Packard, Palo Alto, CA, USA) and a lightwave multimeter (8163A, Santa Clara, CA, USA). The laser source specifications are listed in Table 3. Multimode silica fibers with a diameter of $62.5 \mu \mathrm{m}$ were connected to the source and the multimeter, and the sapphire fibers were placed between those fibers as shown in Figure 2 and Figure 3. Micrometer-driven three-axis stages were employed to align the sapphire fibers and silica fibers. An index matching liquid was also used at the junction of sapphire fibers and leadin/lead-out fibers to reduce the losses. The attenuation spectrum was obtained at an input power of $0 \mathrm{dBm}$ in $1500-1590 \mathrm{~nm}$ range with $1 \mathrm{~nm}$ steps. A picture of a signal in the visible spectrum (from another laser source) passing through an embedded fiber is shown in Figure 4 for demonstrative purpose.

Table 3. Tunable laser source specifications.

\begin{tabular}{|c|c|c|c|}
\hline $\begin{array}{c}\text { Maximum } \\
\text { power }\end{array}$ & $\begin{array}{c}\text { Beam } \\
\text { diameter }\end{array}$ & $\begin{array}{c}\text { Numerical } \\
\text { aperture }\end{array}$ & Wavelength \\
\hline $10 \mathrm{dBm}$ & $9 \mu \mathrm{m}$ & 0.1 & $1450-1590 \mathrm{~nm}$ \\
\hline
\end{tabular}

\subsection{Mechanical tests}

The size of the blocks before and after sintering was measured to calculate the amount of shrinkage during the sintering processes. Archimedes' test was performed to measure the density of the printed parts after sintering. After the dry mass was recorded, samples were saturated by submersion in distilled water under vacuum for $\sim 12 \mathrm{~h}$. The saturated and suspended masses were then measured to calculate the final density.

Four-point flexural tests were performed at room temperature according to ASTM C1161 [29] to examine the effect of embedded sensors on the strength of the parts. A fully automated surface grinder (FSG-3A818, Chevalier, Santa Fe Springs, CA, USA) was used to machine the parts to standard "A" bars $\left(1.5 \times 2 \times 25 \mathrm{~mm}^{3}\right)$. The bars were machined with a 600 -grit diamond abrasive wheel. Each bar was ground to have a fiber close (typically, tens of micrometers) to its tensile surface so that the effect of fibers on strength would be more prominent. Flexural strengths were measured using a semi-articulating A-bar fixture with an outer span of $20 \mathrm{~mm}$ and an inner span of $10 \mathrm{~mm}$ in a screw-driven instrumented load frame (5881, Instron, Norwood, MA, USA). The crosshead speed was $0.2 \mathrm{~mm} / \mathrm{min}$.

Vickers indentation test was carried out near the embedded fibers according to ASTM C1327 [30] using a microhardness tester (Duramin 5, Struers, Cleveland, OH, USA) to examine the 
local effect of fibers on the hardness. Samples were polished to a $0.25 \mu \mathrm{m}$ diamond finish. The indenter was pressed against the parts with a force of 4.91 or $9.81 \mathrm{~N}$ for $10 \mathrm{~s}$. The indentation size was measured using an optical microscope with a $40 \mathrm{X}$ lens.

Micrographs of cross-sections of fibers and parts as well as fracture surface of broken samples were obtained using optical (KH-3000, Hirox, Hackensack, NJ, USA) and scanning electron (Helios Nanolab 600, FEI, Hillsboro, OR, USA) microscopy.

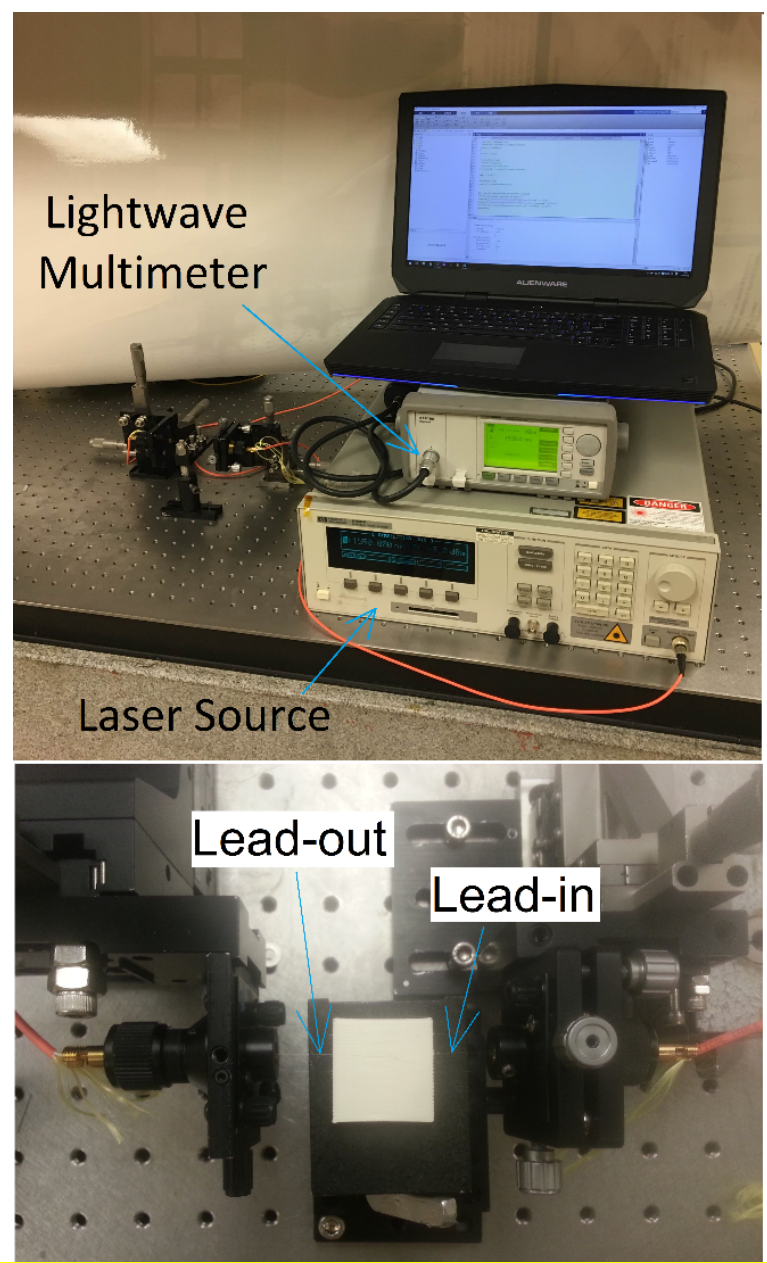

Figure 2. The experimental setup for measuring optical attenuation.

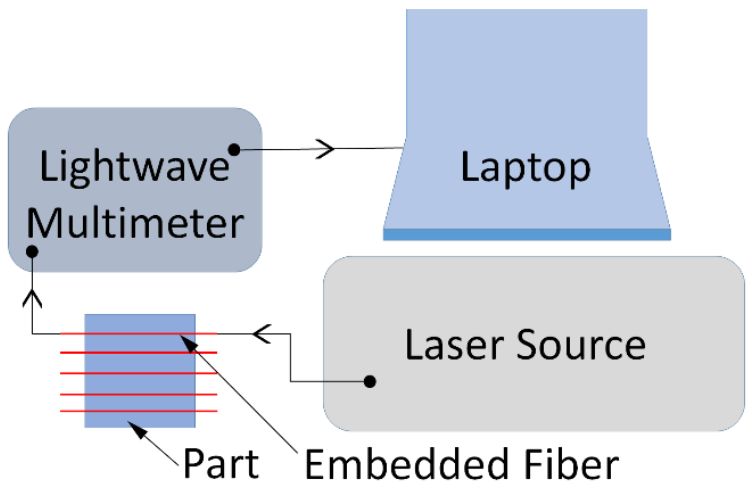


Figure 3. A schematic of the experimental setup for measuring optical attenuation.

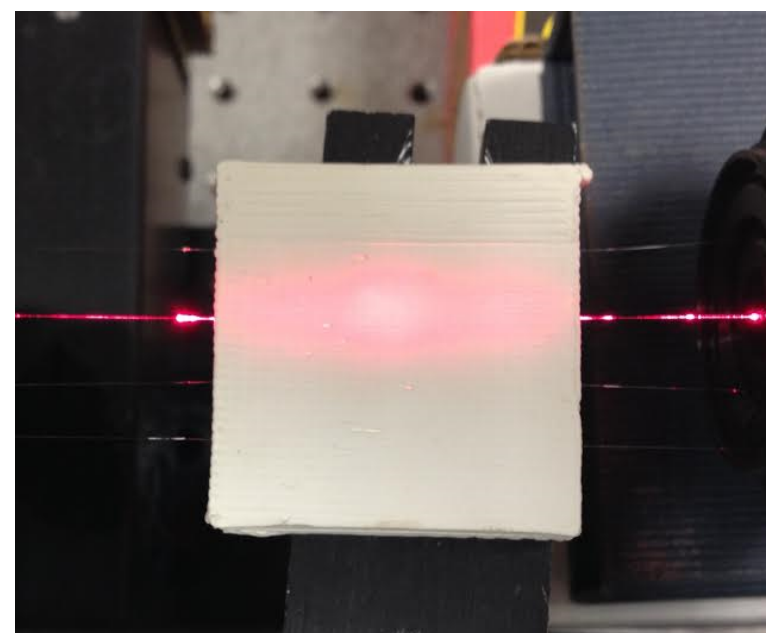

Figure 4. A signal in the visible spectrum passing through an embedded fiber (for demonstrative purpose).

\section{Results and discussion}

A total number of six blocks with embedded fibers were fabricated, out of which two were freeze dried (one with five fibers of $125 \mu \mathrm{m}$ and the other with five fibers of $250 \mu \mathrm{m}$ ) and four were humid dried (two with five $125 \mu \mathrm{m}$ fibers and two with five $250 \mu \mathrm{m}$ fibers). After sintering, parts with $125 \mu \mathrm{m}$ fibers did not have any observable flaws but were slightly warped as shown in Figure 5 (a) and Figure 6 (a). However, the freeze dried part with $250 \mu \mathrm{m}$ fibers was considerably warped and some cracks around the fibers were visible (Figure 5 (b)). Both humid dried parts with $250 \mu \mathrm{m}$ fibers were nearly broken in half (one of them is shown in Figure 6 (b)).

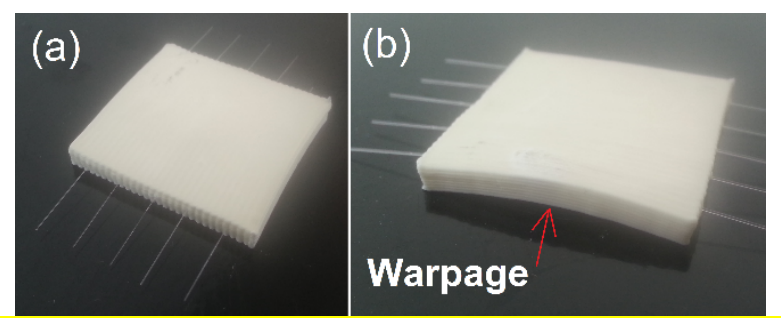

Figure 5. Freeze dried parts with $125 \mu \mathrm{m}$ fibers (a) and $250 \mu \mathrm{m}$ fibers (b).

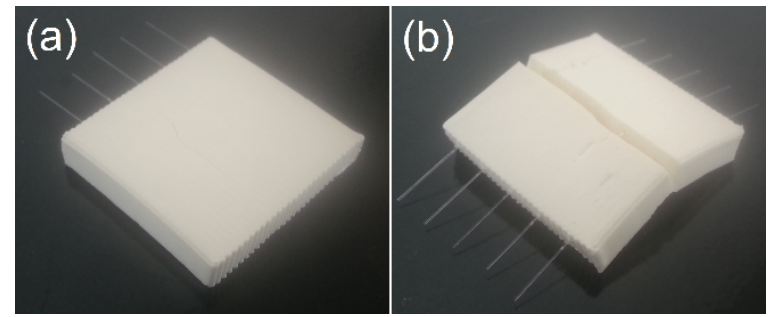

Figure 6. Humid dried parts with $125 \mu \mathrm{m}$ fibers (a) and $250 \mu \mathrm{m}$ fibers (b).

The amount of shrinkage and relative densities of the samples after sintering are given in Table 4. More shrinkage was observed in the vertical direction (height) than in the horizontal directions. However, there was no meaningful difference between the amount of shrinkage in length and width. The densities of freeze dried samples were considerably lower than those of 
the humid dried samples. This is partly due to voids caused by ice crystal formation during freezing of samples as discussed in [31]. In addition to that, expansion of water during freezing $(\sim 9 \mathrm{vol} \%)$ results in lower green body density. Furthermore, unlike humid drying where ceramic particles are dispersed in a liquid medium and can easily move during drying (causing shrinkage), in freeze drying, particles are not free to move during the drying process. Accordingly, the relative green density of freeze dried parts are considerably lower than the humid dried parts (61\% vs. 52\%) and a higher sintering temperature/time is required to densify the freeze dried samples.

\begin{tabular}{|c|c|c|c|c|}
\hline & $\begin{array}{l}125 \mu \mathrm{m}, \\
\text { freeze dried }\end{array}$ & $\begin{array}{c}125 \mu \mathrm{m}, \\
\text { humid dried }\end{array}$ & $\begin{array}{c}250 \mu \mathrm{m}, \\
\text { freeze dried }\end{array}$ & $\begin{array}{c}250 \mu \mathrm{m}, \\
\text { humid dried }\end{array}$ \\
\hline $\begin{array}{l}\text { Shrinkage in } \\
\text { length }\end{array}$ & $14 \%$ & $15 \%$ & $14 \%$ & $14 \%$ \\
\hline $\begin{array}{l}\text { Shrinkage in } \\
\text { width }\end{array}$ & $15 \%$ & $17 \%$ & $14 \%$ & $16 \%$ \\
\hline $\begin{array}{c}\text { Shrinkage in } \\
\text { height }\end{array}$ & $17 \%$ & $18 \%$ & $16 \%$ & $18 \%$ \\
\hline $\begin{array}{l}\text { Volumetric } \\
\text { shrinkage }\end{array}$ & $39 \%$ & $42 \%$ & $38 \%$ & $41 \%$ \\
\hline $\begin{array}{l}\text { Relative } \\
\text { density }\end{array}$ & $93 \%$ & $98 \%$ & $92 \%$ & $98 \%$ \\
\hline
\end{tabular}

The failure of humid dried parts could also be explained considering their density. Since they were denser than freeze dried parts they had a higher Young's modulus, thus the same amount of strain caused by shrinkage of the part and its slippage on the fibers during sintering resulted in higher stresses in them. In the case of $250 \mu \mathrm{m}$ fibers, the contact area between part and fiber was twice as much as that for $125 \mu \mathrm{m}$ fibers and the force became big enough to cause fracture (in humid dried parts) or warpage/cracks (in freeze dried parts). Fortunately, for smaller fibers (whether humid dried or freeze dried) the stresses were not large enough to warp/fracture the part or the fiber. However, further evidence is required to confirm this hypothesis.

Several micrographs of embedded fibers are shown in Figures 7-10. Figure 7 shows a typical micrograph of embedded $125 \mu \mathrm{m}$ fibers. There is a good bonding between fiber and part and no severe damage to part/fiber is observed. However, for humid dried parts, a slight damage to the surface of fibers is revealed at higher magnifications as seen in Figure 8.

As mentioned earlier, cracks formed in freeze dried parts near some of the $250 \mu \mathrm{m}$ fibers as could be seen in Figure 9. However, the micrographs of fractured parts (i.e. humid dried with $250 \mu \mathrm{m}$ fibers) were free of flaws even at high magnifications (Figure 10). 


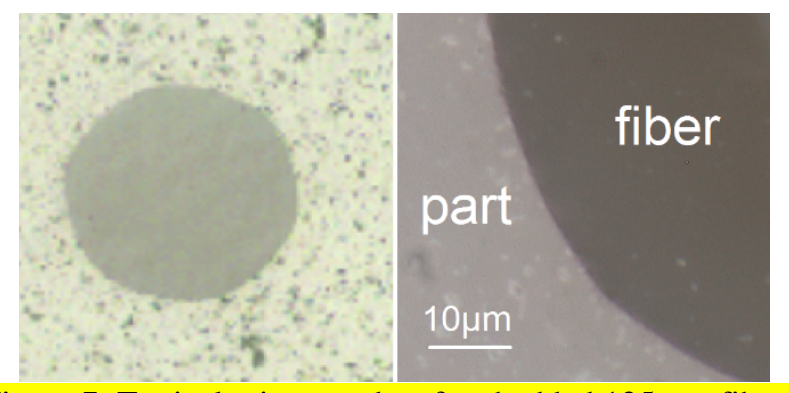

Figure 7. Typical micrographs of embedded $125 \mu \mathrm{m}$ fibers.

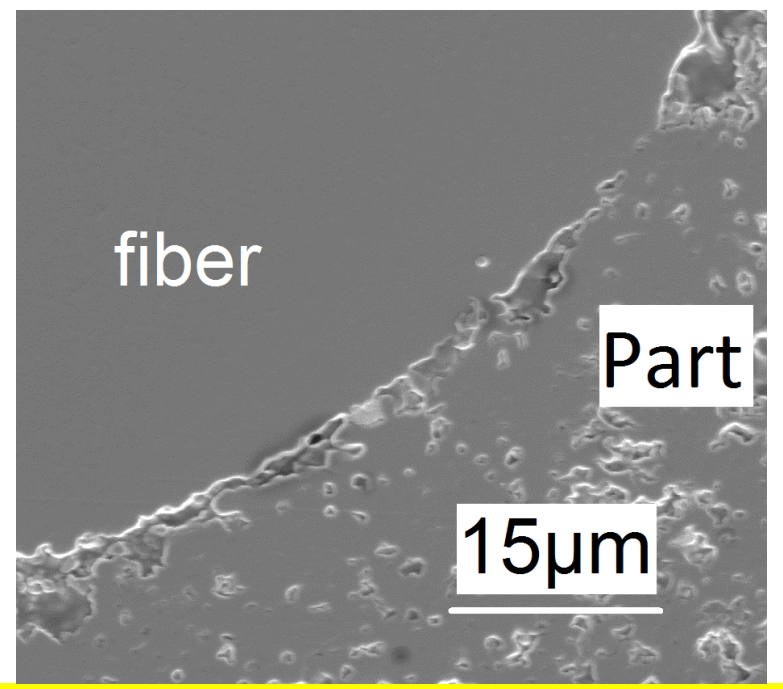

Figure 8. Slight damage to the surface of $125 \mu \mathrm{m}$ fibers when humid dried parts are sintered.

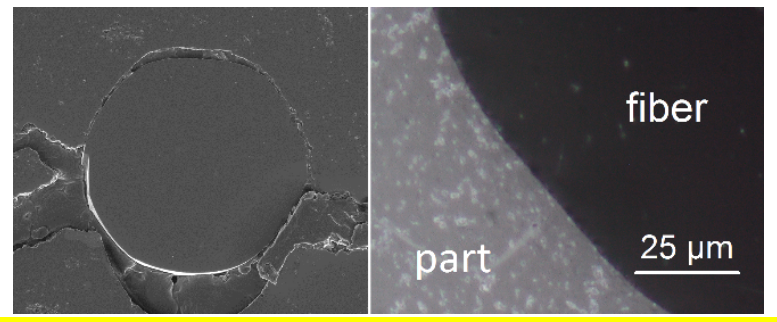

Figure 9. Typical micrographs of freeze dried parts with embedded $250 \mu \mathrm{m}$ fibers.

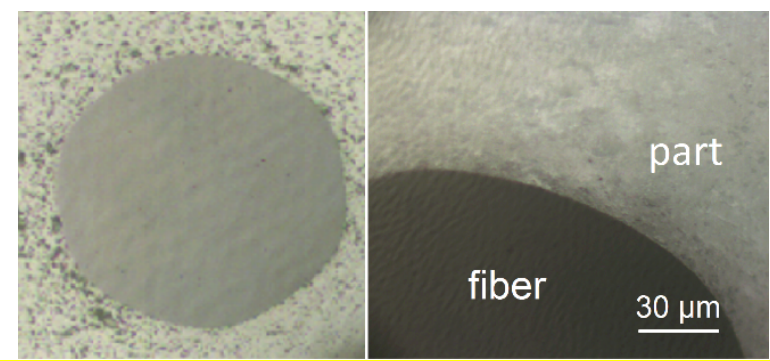

Figure 10. Typical micrographs of humid dried parts with embedded $250 \mu \mathrm{m}$ fibers.

\subsection{Attenuation}

The typical attenuation spectra of optical signals passing through as-received (not embedded) sapphire fibers of 125 and $250 \mu \mathrm{m}$ diameter in the range of $1500-1590 \mathrm{~nm}$ for a $0 \mathrm{dBm}$ input are 
plotted in Figure 11. The amount of attenuation is clearly much larger than specified by the manufacturer (Table 1) mainly due to large mismatch between the diameter of sapphire fibers and silica input/output fibers, the gap between fibers, and the numerical aperture of the lead-in fiber. These effects are schematically shown in Figure 12. There are also other reasons with a smaller contribution; the fibers have an approximately rounded hexagonal cross-section, their surface and ends (although polished) are not perfectly smooth, and the sapphire crystal is uniaxial. The attenuation of the signal is considerably higher for $250 \mu \mathrm{m}$ fiber due to larger mismatch in diameter.

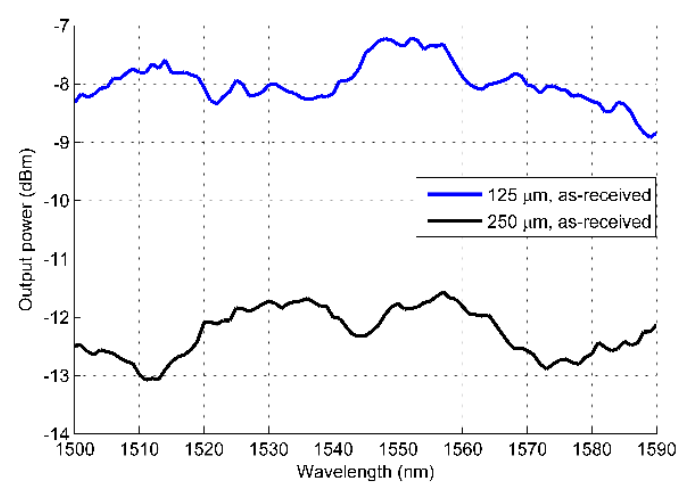

Figure 11. Output power from as-received fibers at different wavelengths for an input power of $0 \mathrm{dBm}$.

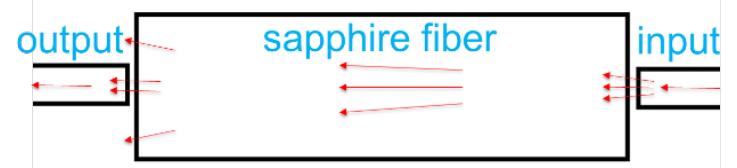

Figure 12. A schematic of losses in transmitted power as a result of input numerical aperture and diameter mismatch.

These losses could be greatly reduced, however. Since the objective was to compare the attenuation before and after embedment, no action was taken to reduce these losses. It should also be noted that the dependency of attenuation on signal wavelength, i.e. fluctuations in Figure 11, was random and not repeatable (even if the same fiber was tested after being slightly repositioned). This is due to a well-known optical fiber concept referred to as multimodal interferences based on a singlemode-multimode-singlemode (SMS) fiber structure [32]. SMS spectrum is very sensitive to position. Even $50 \mathrm{~nm}$ position change alters the spectrum considerably. Although multimode fibers are used as lean in/out fibers, they have a limited number of optical modes which can be considered as nearly singlemode in comparison with highly multimode sapphire fibers.

The relative transmission of embedded fibers compared to as-received fibers are plotted in Figure 13. The average values are also reported in Table 5. As expected, $125 \mu \mathrm{m}$ fibers embedded in freeze dried parts had the lowest loss (transmitting an average of $79 \%$ of power compared to as-received fibers) and $250 \mu \mathrm{m}$ fibers embedded in humid dried parts had the highest loss (passing only $0.0008 \%$ of power relative to as-received $250 \mu \mathrm{m}$ fibers due to severe bending). 


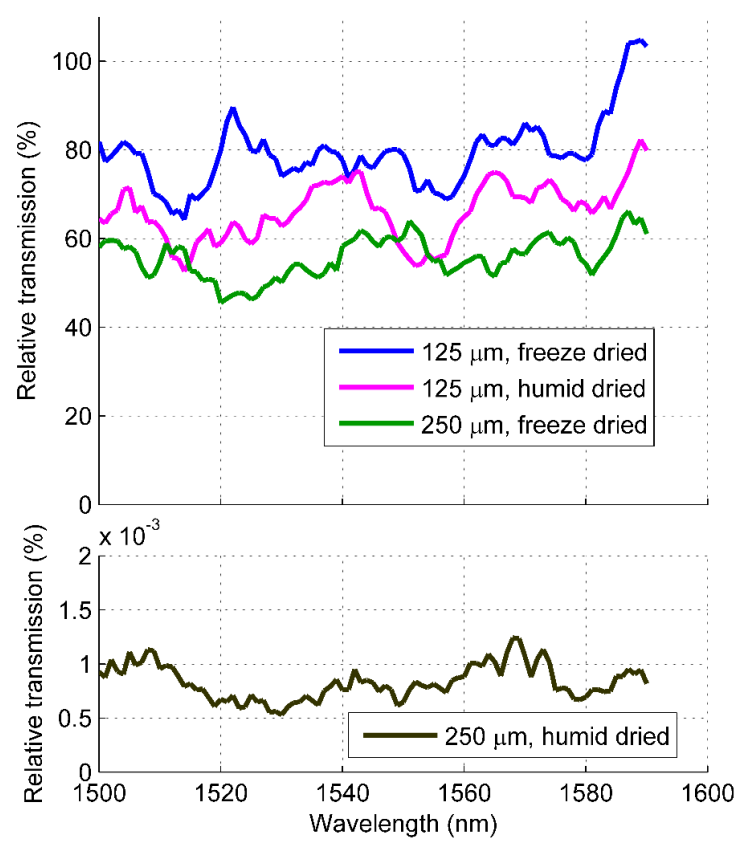

Figure 13. Transmission of fibers after embedment and post-processing, relative to as-received fibers.

Table 5. Average transmission of fibers, relative to as-received fibers.

\begin{tabular}{|c|c|c|c|c|}
\hline & $\begin{array}{c}\mathbf{1 2 5} \boldsymbol{\mu m}, \\
\text { freeze dried }\end{array}$ & $\begin{array}{c}\mathbf{1 2 5} \boldsymbol{\mu m}, \\
\text { humid dried }\end{array}$ & $\begin{array}{c}\mathbf{2 5 0} \boldsymbol{\mu m}, \\
\text { freeze dried }\end{array}$ & $\begin{array}{c}\mathbf{2 5 0} \boldsymbol{\mu m}, \\
\text { humid dried }\end{array}$ \\
\hline $\begin{array}{c}\text { Average } \\
\text { relative } \\
\text { transmission }\end{array}$ & $79 \%$ & $66 \%$ & $56 \%$ & $0.0008 \%$ \\
\hline
\end{tabular}

The most important factor for these losses is believed to be warpage of parts causing losses inside the fibers as well as at the input/output. Another reason is damage to the surface of fibers during the sintering process as shown in Figure 8. This damage is more severe for humid dried parts experiencing more shrinkage than freeze dried parts. Furthermore, residual stresses might also contribute to losses. This has been verified for silica optical fibers (e.g. in [33]) and could also be true for sapphire fibers. Nevertheless, the amount of losses is acceptable for the first three cases and they could potentially be used as sensors to measure the strains in the parts resulted from thermal or mechanical loads.

In the future, the feasibility of successful embedment of large fibers will be studied by "constrained" sintering of parts. A mechanical load will be applied during sintering to preclude shrinkage in the longitudinal direction and reduce slippage of the part on the fibers. This could also reduce the losses for smaller fibers by preventing bending during sintering. Another potential solution to reduce losses is coating the fibers with protective layers before embedding them.

\subsection{Mechanical properties}

The average flexural strengths of test bars were 208, 391, and $152 \mathrm{MPa}$ for freeze dried bars with $125 \mu \mathrm{m}$ fibers, humid dried bars with $125 \mu \mathrm{m}$ fibers, and freeze dried bars with $250 \mu \mathrm{m}$ 
fibers, respectively (as mentioned before, humid dried parts with $250 \mu \mathrm{m}$ fibers fractured during sintering). There were 10 samples for measuring flexural strength of humid dried parts with 125 $\mu \mathrm{m}$ fibers and 5 samples for measuring flexural strength of freeze dried parts with $125 \mu \mathrm{m}$ fibers. The actual strength of freeze dried bars with $250 \mu \mathrm{m}$ fibers was probably lower than the measured value since three of the bars fractured during grinding, which indicates a very low strength. Furthermore, the data for this group is not reliable because it is based on only two samples. Table 6 lists the flexural strengths of bars with embedded fibers as well as bars without fibers fabricated using the same procedure in another study by Ghazanfari et al. [34]. The average hardness values near the fibers were 14.9, 17.1, and 13.8 GPa for freeze dried bars with $125 \mu \mathrm{m}$ fibers, humid dried bars with $125 \mu \mathrm{m}$ fibers, and freeze dried bars with $250 \mu \mathrm{m}$ fibers, respectively. These values are also listed in Table 6 along with obtained values for parts without fibers from the same study by Ghazanfari et al. [34]. Figure 14 shows an example of indented surface for hardness measurements near a fiber.

Table 6. Flexural strength and hardness of samples.

\begin{tabular}{|l|c|c|c|c|c|}
\hline & $\begin{array}{c}\mathbf{1 2 5} \boldsymbol{\mu m}, \\
\text { freeze dried }\end{array}$ & $\begin{array}{c}\mathbf{1 2 5} \boldsymbol{\mu m}, \\
\text { humid dried }\end{array}$ & $\begin{array}{c}\mathbf{2 5 0} \boldsymbol{\mu m}, \\
\text { freeze dried }\end{array}$ & $\begin{array}{c}\text { No fiber, } \\
\text { freeze dried }\end{array}$ & $\begin{array}{c}\text { No fiber, } \\
\text { humid dried }\end{array}$ \\
\hline Strength (MPa) & $208 \pm 37$ & $391 \pm 42$ & $152 \pm 54$ & $330 \pm 57$ & $404 \pm 41$ \\
\hline Hardness $(\mathrm{GPa})$ & $14.9 \pm 0.4$ & $17.1 \pm 0.2$ & $13.8 \pm 0.8$ & $14.5 \pm 0.4$ & $18.7 \pm 0.3$ \\
\hline
\end{tabular}

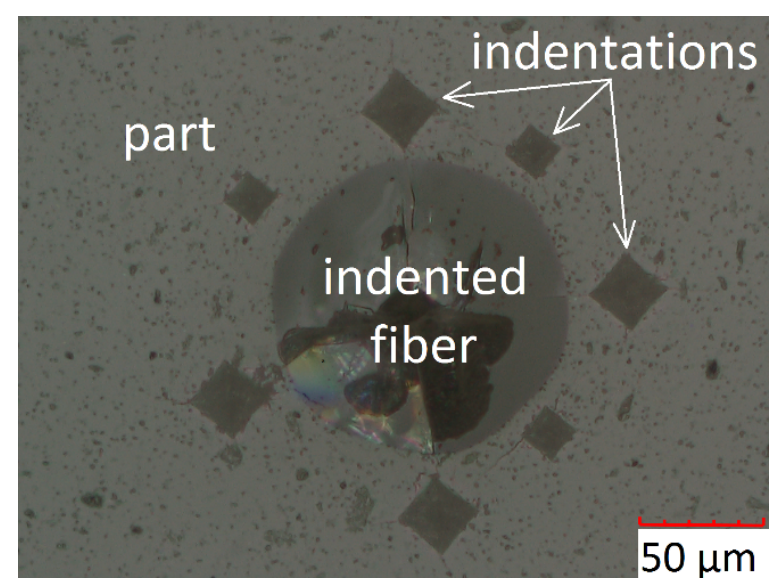

Figure 14. Indentations near a $125 \mu \mathrm{m}$ fiber used to measure hardness.

The inferior properties of freeze dried bars with $250 \mu \mathrm{m}$ fibers were expected due to presence of cracks and residual stresses. For humid dried bars with $125 \mu \mathrm{m}$ fibers, properties are only slightly lower than parts with no fibers which is another evidence of aptness of the proposed method of fabricating smart parts. However, the considerable decrease in flexural strength of freeze dried bars with $125 \mu \mathrm{m}$ fibers was unforeseen and further study is needed to confirm and explain this degradation.

Figure 15 provides typical 2D and 3D views of fracture surfaces near the fibers. Except freeze dried bars with $250 \mu \mathrm{m}$ fibers, no fracture origins could be observed near the fibers. 


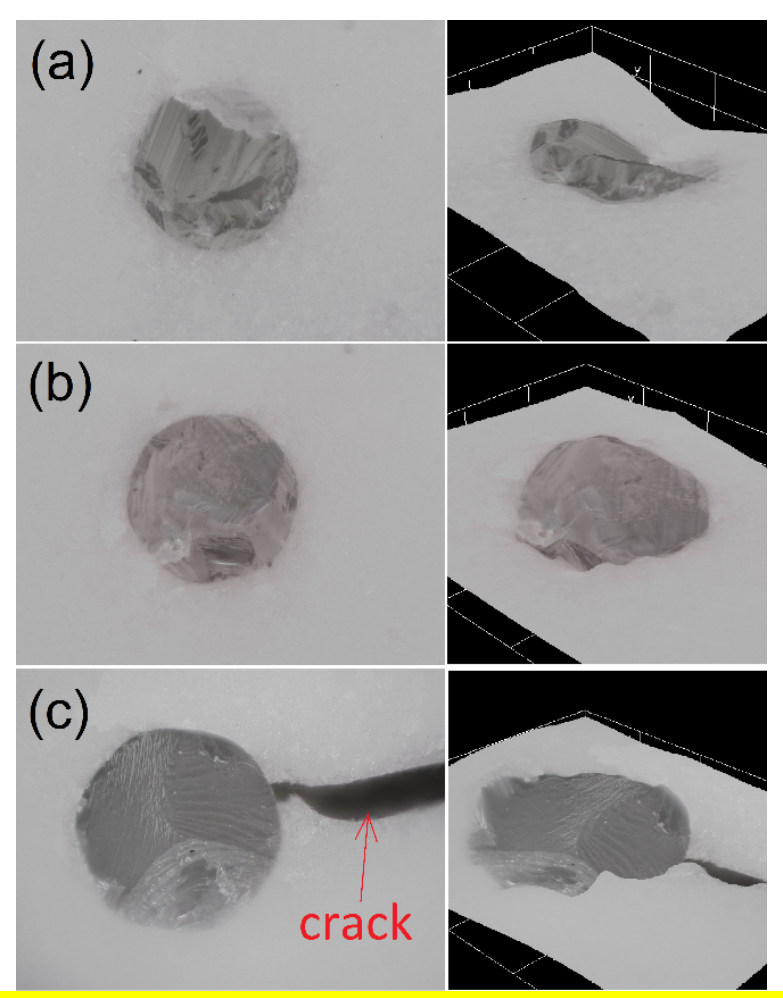

Figure 15. 2D and 3D images of fracture surface of a freeze dried bar with $125 \mu \mathrm{m}$ fibers (a), a humid dried bar with $125 \mu \mathrm{m}$ fibers (b), and a freeze dried bar with $250 \mu \mathrm{m}$ fibers (c).

\section{Conclusions}

An additive manufacturing process using ceramic on-demand extrusion has been employed to study embedding sapphire optical fiber sensors in alumina components during the fabrication process. Two groups of fibers were used: 15 fibers of $125 \mu \mathrm{m}$ diameter and 15 fibers of $250 \mu \mathrm{m}$ diameter. Two different methods were investigated for drying parts after fabrication, and they resulted in two different final relative densities ( 92\% and $\sim 98 \%)$. The results of microscopy, attenuation tests, and mechanical tests indicate that as the diameter of the fibers and relative density of the parts increase, it becomes more challenging to successfully embed the fibers. Nevertheless, for smaller fibers $(125 \mu \mathrm{m}$ diameter) the parts and the embedded fibers are functional. Thus, they could potentially be used to measure the strains in the parts generated by thermal and/or mechanical loads.

\section{$\underline{\text { Acknowledgements }}$}

The authors gratefully acknowledge the financial support by the National Energy Technology Laboratory of the U.S. Department of Energy's Office of Fossil Energy under the contract DEFE0012272, and the Intelligent Systems Center at the Missouri University of Science and Technology.

\section{$\underline{\text { References }}$}

[1] A. Raghavan, C.E.S. Cesnik, Review of guided-wave structural health monitoring, Shock Vib. Dig. 39 (2007) 91-114. doi:10.1177/0583102406075428. 
[2] M. Majumder, T.K. Gangopadhyay, A.K. Chakraborty, K. Dasgupta, D.K. Bhattacharya, Fibre Bragg gratings in structural health monitoring-Present status and applications, Sensors Actuators, A Phys. 147 (2008) 150-164. doi:10.1016/j.sna.2008.04.008.

[3] M.R. Werner, W.R. Fahrner, Review on materials, microsensors, systems, and devices for high-temperature and harsh-environment applications, IEEE Trans. Ind. Electron. 48 (2001) 249-257.

[4] W.L. Schulz, J.P. Conte, E. Udd, Long gage fibre optic Bragg grating strain sensors to monitor civil structures, in: Proc. SPIE 4330, Smart Struct. Mater. 2001 Smart Syst. Bridg. Struct. Highw., Newport Beach, CA, USA, 2001: p. 56. doi:10.1117/12.434156.

[5] Z. Zhou, T.W. Graver, L. Hsu, J.P. Ou, Techniques of advanced FBG sensors: fabrication, demodulation, encapsulation and their applications in the structural health monitoring of bridges, Pac. Sci. Rev. 5 (2003) 116-121.

[6] B.K.A. Ngoi, J. Paul, L.P. Zhao, Z.P. Fang, Enhanced lateral pressure tuning of fiber Bragg gratings by polymer packaging, Opt. Commun. 242 (2004) 425- 430.

[7] J.S. Leng, G.C. Mays, G.F. Fernando, Structural NDE of concrete structures using protected EFPI and FBG sensors, Sens. Actuators A. 126 (2006) 340-347.

[8] T.A. Dawood, R.A. Shenoi, M. Sahin, A procedure to embed fibre Bragg grating strain sensors into GFRP sandwich structures, Compos. A. 38 (2007) 217-226.

[9] S. Lu, H. Xia, Strengthen and real-time monitoring of RC beam using "intelligent" CFRP with embedded FBG sensors, J. Constr. Build. Mater. 21 (2007) 1839-1845.

[10] W. Chung, D. Kang, Full-scale test of a concrete box girder using FBG sensing system, Eng. Struct. 30 (2008) 643-652.

[11] K. Kesavan, K. Ravisankar, S. Parivallal, P. Sreeshylam, S. Sridhar, Experimental studies on fiber optic sensors embedded in concrete, Meas. J. Int. Meas. Confed. 43 (2010) $157-$ 163. doi:10.1016/j.measurement.2009.08.010.

[12] M. Raymond, Structural monitoring with fiber optic technology, Academic Press, California, 2001.

[13] G. Pereira, C. Frias, H. Faria, O. Frazao, A.T. Marques, Study of strain-transfer of FBG sensors embedded in unidirectional composites, Polym. Test. 32 (2013) 1006-1010. doi:10.1016/j.polymertesting.2013.05.006.

[14] J. Chilles, A. Croxford, I.P. Bond, Design, application, and validation of embedded ultrasonic sensors within composite materials, in: P.J. Shull (Ed.), Proc. SPIE 9437, Struct. Heal. Monit. Insp. Adv. Mater. Aerospace, Civ. Infrastruct., Sad Diego, CA, USA, 2015. doi:10.1117/12.2083944.

[15] J.S. Chilles, A. Croxford, I.P. Bond, Design of an embedded sensor, for improved structural performance, Smart Mater. Struct. $24 \quad$ (2015). doi:http://dx.doi.org/10.1088/0964-1726/24/11/115014.

[16] X. Li, X. Zhang, D. Werschmoeller, H. Choi, X. Cheng, Embedded micro/nano sensors for harsh engineering environments, in: Proc. IEEE Sensors Conf., 2008: pp. 1273-1276. doi:10.1109/ICSENS.2008.4716676. 
[17] G.D. Janaki Ram, C. Robinson, Y. Yang, B.E. Stucker, Use of ultrasonic consolidation for fabrication of multi-material structures, Rapid Prototyp. J. 13 (2007) 226-235. doi:10.1108/13552540710776179.

[18] Y. Li, W. Liu, Y. Feng, H. Zhang, Ultrasonic embedding of nickel-coated fiber Bragg grating in aluminum and associated sensing characteristics, Opt. Fiber Technol. 18 (2012) 7-13. doi:10.1016/j.yofte.2011.09.004.

[19] R.R.J. Maier, W.N. Macpherson, J.S. Barton, M. Carne, M. Swan, J.N. Sharma, S.K. Futter, D.A. Knox, B.J.S. Jones, S. McCulloch, Embedded fiber optic sensors within additive layer manufactured components, IEEE Sens. J. 13 (2013) 969-979.

[20] M.J. Dapino, Smart structure integration through ultrasonic additive manufacturing, in: ASME 2014 Conf. Smart Mater. Adapt. Struct. Intell. Syst., Newport, Rhode Island, USA, 2014: pp. 1-8.

[21] T. Monaghan, A.J. Capel, S.D. Christie, R.A. Harris, R.J. Friel, Solid-state additive manufacturing for metallized optical fiber integration, Compos. Part A Appl. Sci. Manuf. 76 (2015) 181-193. doi:10.1016/j.compositesa.2015.05.032.

[22] J. Li, T. Monaghan, S. Masurtschak, A. Bournias-Varotsis, R.J. Friel, R.A. Harris, Exploring the mechanical strength of additively manufactured metal structures with embedded electrical materials, Mater. Sci. Eng. A. 639 (2015) 474-481. doi:10.1016/j.msea.2015.05.019.

[23] C. Kousiatza, D. Karalekas, In-situ monitoring of strain and temperature distributions during fused deposition modeling process, Mater. Des. 97 (2016) 400-406. doi:10.1016/j.matdes.2016.02.099.

[24] N. Travitzky, A. Bonet, B. Dermeik, T. Fey, I. Filbert-Demut, L. Schlier, T. Schlordt, P. Greil, Additive manufacturing of ceramic-based materials, Adv. Eng. Mater. 16 (2014) 729-754. doi:10.1002/adem.201400097.

[25] K.O. Hill, G. Meltz, Fiber Bragg grating technology fundamentals and overview, J. Light. Technol. 15 (1997) 1263-1276. doi:10.1109/50.618320.

[26] G.N. Merberg, J.A. Harrington, Optical properties of single-crystal sapphire fibers, Appl. Opt. 32 (1993) 3201-3209. doi:10.1364/AO.36.005934.

[27] J. Huang, X. Lan, Y. Song, Y. Li, L. Hua, H. Xiao, Microwave interrogated sapphire fiber michelson interferometer for high temperature sensing, IEEE Photonics Technol. Lett. 27 (2015) 1398-1401. doi:10.1109/LPT.2015.2422136.

[28] A. Ghazanfari, W. Li, M.C. Leu, G.E. Hilmas, A novel extrusion-based additive manufacturing process for ceramic parts, in: D. Bourell, J. Beaman, R. Crawford, S. Fish, H. Marcus, C. Seepersad (Eds.), Solid Free. Fabr. Symp., Austin, TX, USA, 2016.

[29] ASTM C1161, Standard test method for flexural strength of advanced ceramics at ambient temperatures, West Conshohocken, PA, USA, 2013. doi:10.1520/C1161-13.

[30] ASTM C1327, Standard test method for Vickers indentation hardness of advanced ceramics, West Conshohocken, PA, USA, 2015. doi:10.1520/C1327-15.

[31] J. Li, M.C. Leu, G.E. Hilmas, Effects of temperature on aqueous freeform extrusion 
fabrication, in: D. Bourell, J. Beaman, R. Crawford, S. Fish, H. Marcus, C. Seepersad (Eds.), Solid Free. Fabr. Symp., Austin, TX, USA, 2015: pp. 319-331.

[32] Q.W.Q. Wang, G. Farrell, W.Y.W. Yan, Investigation on single-mode-multimode-singlemode fiber structure, J. Light. Technol. 26 (2008) 512-519. doi:10.1109/JLT.2007.915205.

[33] Y. Namihira, M. Kudo, Y. Mushiake, Effect of mechanical stress on the transmission characteristics of optical fiber, Electron. Commun. Japan. 60 (1977) 107-115.

[34] A. Ghazanfari, W. Li, J. Watts, M.C. Leu, Effect of process parameters on properties of parts produced by ceramic on-demand extrusion process, Under Prep. (n.d.). 


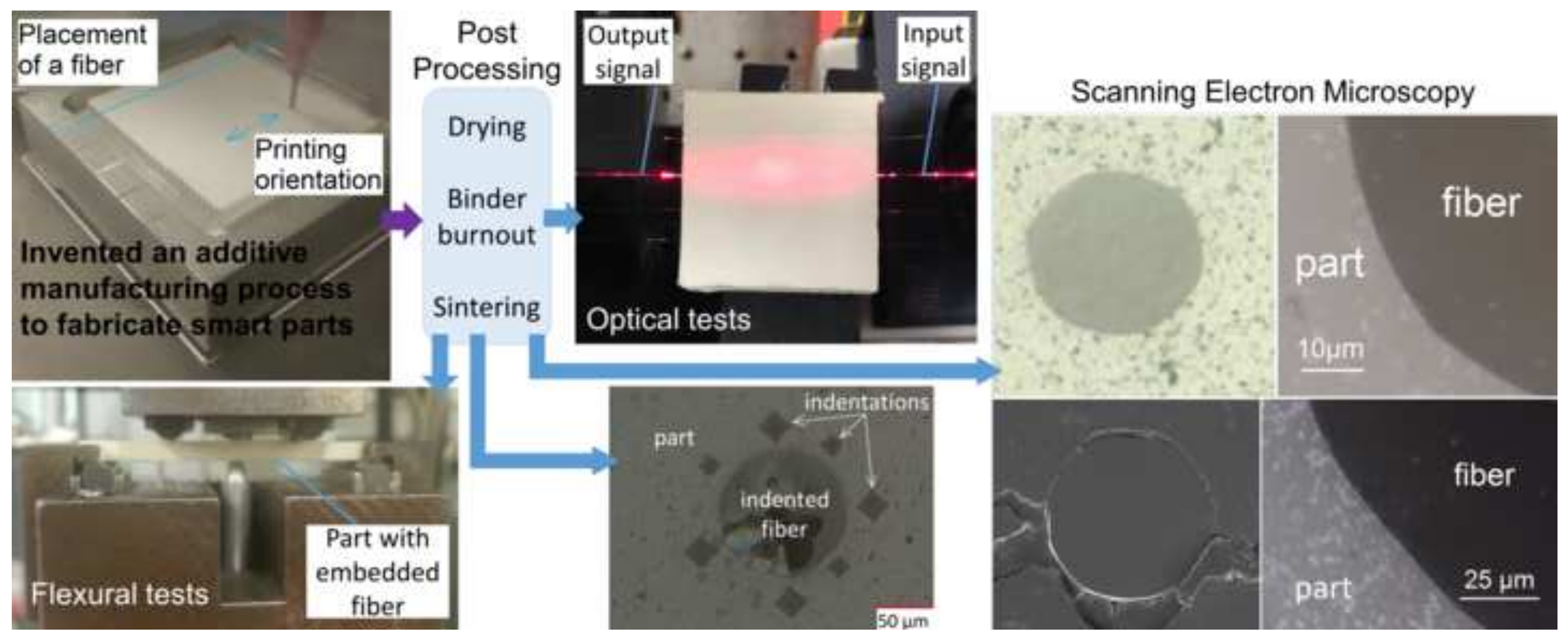

